Presented at: XVIII International Linac Conference

Geneva, Switzerland

August 26-30, 1996

$$
\begin{gathered}
\text { BNL- } 63636 \\
\text { CONF }-9608123--48
\end{gathered}
$$

First Experimental Results of the BNL Inverse Free Electron Laser Accelerator

A. van Steenbergen ${ }^{1}$ J. Gallardo ${ }^{1}$, J. Sandweiss ${ }^{2}$, M. Babzien ${ }^{1}$, J.-M. Fang ${ }^{3}$, X. Qiu ${ }^{4}$, J. Skaritka ${ }^{1}$, X.-J. Wang ${ }^{1}$

\author{
${ }^{1}$ Brookhaven National Laboratory, Upton, NY 11973 \\ ${ }^{2}$ Physics Department, Yale University, New Haven, CT 06511 \\ ${ }^{3}$ Department of Applied Physics, Columbia U., NY 10027 \\ ${ }^{4}$ Physics Department, State University of New York, Stony Brook, NY 11794
}

October 1996

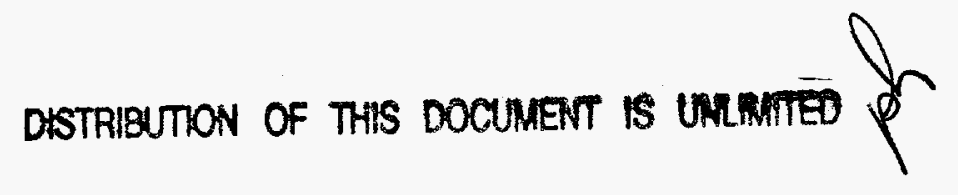
National Synchrotron Light Source
Brookhaven National Laboratory
Upton, NY 11973

Work performed under the auspices of the U.S. Department of Energy, under contract DE-AC02-76CH00016 


\section{DISCLAMMER}

This report was prepared as an account of work sponsored by an agency of the United States Government. Neither the United States Government nor any agency thereof, nor any of their employees, makes any warranty, express or implied, or assumes any legal liability or responsibility for the accuracy, completeness, or usefulness of any information, apparatus, product, or process disclosed, or represents that its use would not infringe privately owned rights. Reference herein to any specific commercial product, process, or service by trade name, trademark, manufacturer, or otherwise does not necessarily constitute or imply its endorsement, recommendation, or favoring by the United States Government or any agency thereof. The views and opinions of authors expressed herein do not necessarily state or reflect those of the United States Government or any agency thereof. 


\section{DISCLAIMER}

Portions of this document may be illegible in electronic image products. Images are produced from the best available original document. 


\title{
FIRST EXPERIMENTAL RESULTS OF THE BNL INVERSE FREE ELECTRON LASER ACCELERATOR
}

\author{
A. van Steenbergen ${ }^{1 *}$, J. Gallardo ${ }^{1 * *}$, J. Sandweiss ${ }^{2}$, M.Babzien', J-M Fang ${ }^{3}$, X.Qiu, J.Skaritka ${ }^{1}$, X-J Wang ${ }^{1}$ \\ 'Brookhaven National Laboratory, Upton NY 11973 \\ ${ }^{2}$ Physics Department, Yale University, New Haven CT 06511 \\ ${ }^{3}$ Department of Applied Physics, Columbia U., New York NY 10027 \\ ${ }^{4}$ Physics Department, State University of New York, Stony Brook, New York 11794
}

\begin{abstract}
A $40 \mathrm{MeV}$ electron beam, using the inverse freeelectron laser interaction, has been accelerated by $\Delta \mathrm{E} / \mathrm{E}=$ $2.5 \%$ over a distance of $0.47 \mathrm{~m}$. The electrons interact with a $1-2 \mathrm{GW} \mathrm{CO}$ laser beam bounded by a $2.8 \mathrm{~mm} \mathrm{DD}$ sapphire circular waveguide in the presence of a tapered wiggler with $B \max =1 \mathrm{~T}$ and a period $2.89 \mathrm{~cm} \leq \lambda_{w} \leq 3.14$ $\mathrm{cm}$. The experimental results of $\triangle \mathrm{E} / \mathrm{E}$ as a function of electron energy $E$, peak magnetic field $B w$ and laser power $W_{1}$ compare well with analytical and 1-D numerical simulations and permit scaling to higher laser power and electron energy.
\end{abstract}

\section{Introduction}

The study of the Inverse-Free Electron-Laser (IFEL) as a potential mode of electron acceleration has been pursued at Brookhaven National Laboratory (BNL) for a number of years [1-4]. Recent studies have focused on the development of a low energy, high gradient, IFEL accelerator [5] as a first step toward a multi-module electron accelerator of maximum operating energy of a few $\mathrm{GeV}$. Experimental verification of the IFEL accelerator concept was obtained in 1992 [6], using a radiation wave length of $\lambda=1.65 \mathrm{~mm}$, and more recently [7] using a wavelength of $10.6 \mu \mathrm{m}$. In this report further experimental evidence of the IFEL interaction $(\lambda=10.6$ $\mu \mathrm{m}$ ) is presented. The experiment used a $50 \mathrm{MeV}$ electron beam, a 1-5 $\mathrm{GW} \mathrm{CO}_{2}$ laser beam provided by BNL's Accelerator Test Facility (ATF) and a uniquely designed period length tapered wiggler.

The wiggler is a fast excitation electromagnet with stackable, geometrically and magnetically alternating substacks of Vanadium Permendur (VaP) ferromagnetic laminations, periodically interspersed with conductive (Cu), nonmagnetic laminations, which act as eddy current induced field reflectors [8,9]. Four current conducting rods, parallel to the wiggler axis, are connected at the ends of the assembly, constituting the excitation loop that drives the wiggler. The overall wiggler stack is easily assembled, is compressed by simple tie rods, and readily permits wiggler period $\left(\lambda_{w}\right)$ variation. Configured as a constant period wiggler, $\lambda_{w}=3.75 \mathrm{~cm}$ and $B_{\max }=1 \mathrm{~T}$, the system has shown [10] an rms pole-to-pole field variation of approximately $0.2 \%$.

The $\mathrm{CO}_{2}$ laser beam is brought into the IFEL interaction region by a low loss dielectric $\left(\mathrm{Al}_{2} \mathrm{O}_{3}\right.$ ,sapphire) circular waveguide which evidenced very good transmission properties [11] of the high power $\mathrm{CO}_{2}$ laser beam. Extensive studies were carried out to establish optimum coupling into the guide and to measure the transmission loss of the long $(1.0 \mathrm{~m})$ extruded single crystal sapphire guides. Also, because of the overmoded guide configuration (ID $=2.8 \mathrm{~mm}$ ), attempts were made to determine the transverse mode spectrum. To this end various wave guide configurations were tested at low laser beam power with the beam focused to a Gaussian waist with adjustable radius at the entrance of the waveguide. The beam profile was measured using a pyroelectric vidicon TV camera combined with digital frame grabber. For the $2.8 \mathrm{~mm}$. ID sapphire dielectric guide a laser power attenuation factor of $0.2 \mathrm{~dB} / \mathrm{m}$ was measured. The laser beam profile within the guide was inferred by measuring the beam diameter at the guide exit for various guide lengths. The results show that, commensurate with the near constant beam profile within the guide, the mode structure is dominated by the guide fundamental mode only. This is in accord with the absence of mode mixing reported in Ref.[11] for filamentary sapphire guides for $\mathrm{CO}_{2}$ laser radiation transport.

In the IFEL accelerator, the electron beam is accelerated by the interaction with the laser radiation wave in the medium of a periodic wiggler field. The theoretical description of the interaction has been given by a number of authors $[3,12]$. Approximate analytical expressions derived in Ref.[3] were used to parameterize a single acceleration stage. Subsequently, $1-D$ and 3-D simulation programs were written solving the self consistent system of Lorentz equations for the electrons and the wave equations for the input laser field as discussed in Ref. [12]. The I-D program has been used to determine the self-consistent wiggler period length and its taper for given values of electron beam energy and laser power and to calculate the bucket acceptance and bucket leakage for a single or multi module accelerator. The 3-D code has been used to study beam drift,transverse phase space distributions and emittance growth. 


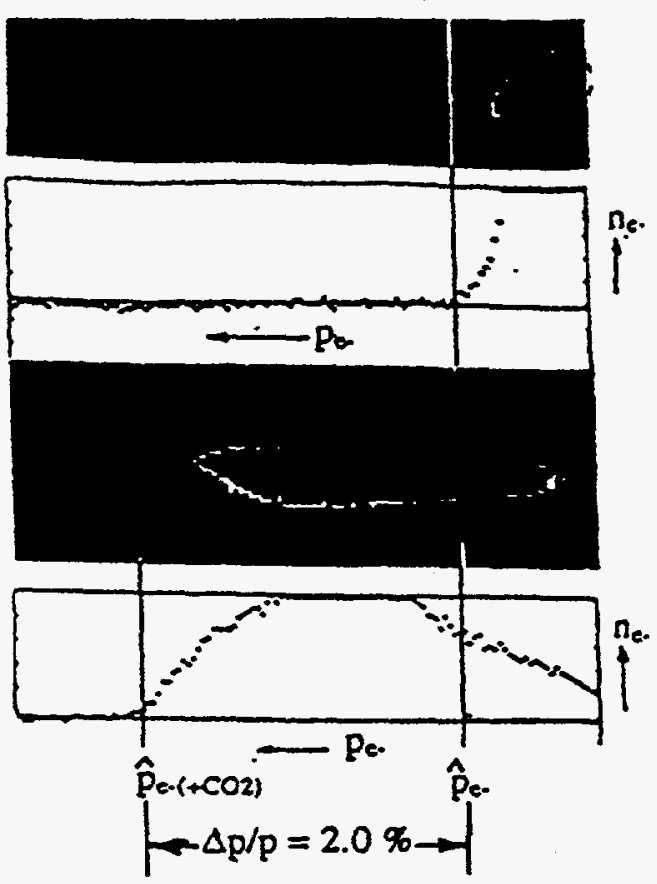

Fig. 2, Momentum Spectrum of the unaccelerated and IFEL accelerated electron Beam $E_{1}=40 \mathrm{MeV}, B_{w}=10 \mathrm{kG}, \lambda_{w}=2.9-3.1 \mathrm{~cm}, W_{1}=1 \mathrm{GW}$

of $35 \mathrm{MeV}$ leads to a value of the magnetic field $B_{w}=$ $8.35 \mathrm{kG}$, to be compared with the experimental value of $8.44 \mathrm{kG}$, and for $E=40 \mathrm{McV}$, the calculated $B_{w}$ is 9.98 $\mathrm{kG}$ and the experimental value was $\mathrm{B}_{w}=9.96 \mathrm{kG}$.

In conclusion, the IFEL acceleration of a $40_{2} \mathrm{MeV}$ electron beam by $\triangle E / E=2.5 \%$ with a $1 \mathrm{GW} \mathrm{CO}_{2}^{-}$laser and a tapered wiggler with peak field on axis of $10 \mathrm{kG}$ has been confirmed. Agreement with the model predictions is satisfactory, permitting the scaling of anticipated results to higher laser power. Present IFEL operation is limited to a maximum laser power of $\leq 2 \mathrm{GW}$. With the upgrading

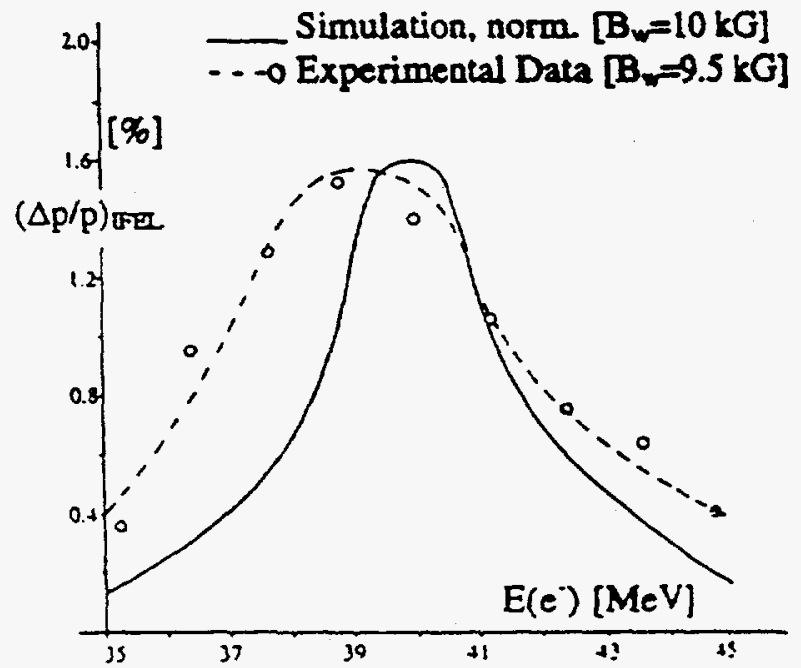

Fig.3, Relative Energy Gain $\triangle E J E$ vs E. with B.. W/ constant



Fig.4, Relative Energy Gain vs $B_{w}$ with $E$ and $W_{1}$ constant

of the ATF $\mathrm{CO}_{2}$ laser to the 1TW level as presently underway, an IFEL mean acceleration gradient of 100 $\mathrm{MeV} / \mathrm{m}$ might become achievable.

The authors wish to acknowledge the invaluable support of the ATF staff K.Batchelor, I.Ben-Zvi, A.Fisher, K. Kusche, R. Malone,I.Pogorelsky,T. Romano, J.Sheehan, T. Srinivasan-Rao .

This work was supported by the Advanced Technology R\&D Branch, Division of High Energy Physics, U.S.Department of Energy, DE-AC02-76CH00016.

\section{References}

[1] R. Palmer, J. Appl. Phys. 43, 3014,1972.

[2] C. Pellegrini, P. Sprangle,W. Zakowicz, Proc. of the XIIInt.Conf. on High Energy Accelerators, p.473,1983.

[3] E. Courant.C. Pellegrini,W. Zakowicz, PR A32, 2813,1985. [4] A. Fisher, J. Gallardo, I. Sandweiss, A.van Steenbergen. "Inverse Free Electron Laser Accelerator". Proc. Adv. Accel. Concepts, Port Jefferson, NY. AIP 279, p.299,1993.

[5] A. Fisher, J. Gallardo, A. van Steenbergen, J. Sandweiss. "IFEL Accelerator Development", Nucl. Instr. Meth.A341,1994 [6] 1. Wernick and T. C. Marshall, Phys. Rev. A46, $3566,1992$. [7]A.vanSteenbergen,J.Gallardo,J.Sandweiss,J.Fang.M.Babzien. K.Batchelor,A.Fisher,K.Kusche.R.Malone.I.Pogorelsky.J.Qiu. T.Romano, J.Sheehan. J.Skaritka, T.Srinivasan-Rao, XJWang. "Inverse Free Electron Laser Single Module e' Acceleration". Proceedings BNL CAPIATF Users Meeting. Dec., 1995 [8]A.van Steenbergen,Pat.Appl.368618,June 1989 (Aug. '90) [9] A. van Steenbergen, J. Gallardo. T. Romano, M. Woodle. "Fast Excitation Wiggler".Proc.PAC SF..JEEE NS. May 1991 [10]A.Fisher.J.Gallardo.A.van Steenbergen.J.Sandweiss,J.Fang. "IFEL Development".VI Workshop Adv. Accel.,Fontana,WI '94 [11] J. Harrington, C. Gregory. Optics Letters 15. (1990)

[12] N.Kroll, P.Morton. M.Rosenbluth.Physics of QE 7,89,1979

(13) 1. Ben-Zvi, Proc. Adv. Accel. Concepts, Port Jefferson, NY, AIP 279. 590 (1993)

[14] 1. Pogorelsky. Proc. Adv. Accel. Concepts, Port Jefferson. NY. AlP 279608 (1993) 